Boise State University

ScholarWorks

Biology Faculty Publications and Presentations

Department of Biological Sciences

$12-1-2017$

\title{
Flushing Responses of Golden Eagles (Aquila chrysaetos) in Response to Recreation
}

Robert J. Spaul

Boise State University

Julie A. Heath

Boise State University 


\title{
FLUSHING RESPONSES OF GOLDEN EAGLES (AQUILA CHRYSAETOS) IN RESPONSE TO RECREATION
}

\author{
ROBERT J. SPAUL ${ }^{1,2}$ AND JULIE A. HEATH ${ }^{1}$
}

\begin{abstract}
Disturbance because of human activity, including recreation on wildlands, can affect bird behavior which in turn can reduce breeding success, an important consideration for species of management concern. We observed Golden Eagles (Aquila chrysaetos) during the breeding season to determine whether the probability of flushing was affected by the type of recreationist, distance to encounter, eagle nest attendance, or date. We monitored eagles in 23 nesting territories from distant (600-1,200 m) observation points and recorded recreation activity within 1,200 $\mathrm{m}$ of eagles in the Owyhee Front of southwestern Idaho. In most $(86 \%, n=270)$ encounters, eagles did not flush in response to recreationists; however, whether an eagle flushed was affected by the type of recreationist and whether an eagle was at or away from the nest. Eagles were 60 times more likely to flush in response to recreationists that stopped a motor vehicle and transitioned to walking (11 of 17 passes) and 4.5 times more likely to flush in response to off-road vehicle (ORV) riders (17 of 121 passes) than during encounters with road vehicles ( 7 of 107 passes). Flushing was 12 times more likely for eagles away from nests (23 of 87 passes) than eagles at nests (13 of 183 passes). Eagles flushed at greater distances in response to recreationists that transitioned from motor vehicles to walking $(1 \mathrm{smean}=620 \mathrm{~m})$ than when responding to either ORV riders $(1 \mathrm{smean}=525 \mathrm{~m})$ or road vehicles (lsmean $=318 \mathrm{~m}$ ). Flushing distances tended to decline throughout the breeding season to suggest seasonal changes in the costs and benefits of responding to disturbance. After flushing from nests, most eagles ( $77 \%$ ) spent $<40$ mins away, but some $(23 \%)$ spent $>90$ mins away from nests. Limiting recreational activities within $650 \mathrm{~m}$ and $1,000 \mathrm{~m}$ of nest sites may decrease nest-site flushing events by $77 \%$ and $100 \%$, respectively. Because eagles seem most sensitive to humans transitioning between motorized and non-motorized recreation, land managers may strike a balance between access needs of recreationists and buffering eagles from disturbance by using a mix of trail closures and no-stopping zones that prevent transitions from motorized to walking activities. Received 23 September 2016. Accepted 7 February 2017.
\end{abstract}

Key words: buffer zones, flushing distance, human disturbance, off-road vehicles, pedestrians, raptors, trail management.

Outdoor recreation in public areas leads to more human-wildlife interactions that have consequences, including negative impacts because of human disturbance (Newsome et al. 2013). Human disturbance, the process by which wildlife-human encounters result in alteration of wildlife behavior and/or physiology, has been associated with avoidance behavior (Frid and Dill 2002), physiological stress (Hayward et al. 2011, Strasser and Heath 2013), and impaired sensory perception (Mason et al. 2016). Further, disturbance can lead to changes in habitat use (Gill and Sutherland 2000, Webber et al. 2013), interfere with foraging (Fernández-Juricic and Tellería 2000), alter regimes of self-maintenance (Kight and Swaddle 2007), and reduce parental care to young (Fernández and Azkona 1993, Steidl and Anthony 2000). Ultimately, disturbance could lead to reduced breeding success (Buick and Paton 1989, Brambilla et al. 2004, Watson et al. 2014), which may lead to population declines (Palacios and Mellink 1996, Wiedmann and Bleich 2014, Pauli et al.

\footnotetext{
${ }^{1} 1910$ University Drive, Department of Biological Sciences and Raptor Research Center, Boise State University, Boise, ID 83725, USA.

${ }^{2}$ Corresponding author; e-mail: robspaul@boisestate.edu
}

2017). Management of the effects of recreationbased human disturbance on wildlife requires a better understanding of how animals respond to human activity. Flushing probability, the likelihood of a bird fleeing in response to a human encounter, and flushing distance, the distance between the bird and the human when flushing occurs, are commonly used metrics to gauge wildlife sensitivity to humans and inform management strategies such as buffer distances (González et al. 2006, Weston et al. 2012).

Studies of recreation-wildlife interactions have found that motorized recreation (Buick and Paton 1988, Harris et al. 2014, McGowan and Simons 2006) and non-motorized recreation (Finney et al. 2005, Reed and Merenlender 2008) can lead to changes in wildlife behavior or demographics. There is evidence that some species are more sensitive (i.e., more likely to behaviorally respond or respond at greater distances) to one form of recreation compared to another (González et al. 2006, Brown et al. 2012, Costello et al. 2013). However, little is known about activity-specific responses, because few studies evaluate different forms of recreation within the same study (see González et al. 2006, McLeod et al. 2013). In 
addition to recreation type affecting behavior, wildlife responses to recreation can vary by time of year, proximity to nest sites, or other factors (Livezey et al. 2016). For example, incubating Eurasian Curlews (Numenius arquata) were less responsive to pedestrians later in the breeding season compared to early in the season (de Jong et al. 2013), and Bald Eagles (Haliaeetus leucocephalus) were more likely to flush from perches than nests when approached by a recreationist (Grubb and King 1991).

Golden Eagles (Aquila chrysaetos) are a widespread, but uncommon, species in northern and western North America and are protected under the Bald and Golden Eagle Protection Act (BGEPA) in the United States (16 U.S.C. $§ 668-$ $668 \mathrm{c}$ ). Among other rules, the BGEPA prohibits "take" (i.e., to "pursue, shoot, shoot at, poison, wound, kill, capture, trap, collect, molest or disturb") from human disturbance. The Code of Federal Regulations defines "disturb" as "to agitate or bother...to a degree that causes, or is likely to cause, based on the best scientific information...a decrease in its productivity, by substantially interfering with normal breeding, feeding or sheltering behavior" (50 C.F.R. $\S$ 22.3). To minimize the probability of take, the USFWS recommends exclusionary spatial buffers around Golden Eagles' nests for permanent structures $(\sim 0.80 \mathrm{~km}$ if the structure is out of view of a nest, and $\sim 1.6 \mathrm{~km}$ if it is in view of a nest [M. Stuber, pers. comm.]), but no official federal buffer regulations exist pertaining to recreation activities. On a more local scale, some USFWS offices and state agencies recommend buffer distance for recreation (Romin and Muck 2002, Klute 2008).

In shrub-steppe landscapes, Golden Eagles commonly nest on canyon cliffs near areas that also attract people engaging in many forms of recreation. Steenhof et al. (2014) showed that the number of young eagles produced per nesting territory (an area that contains, or historically contained, one or more nests within the home range of a mated pair [Steenhof and Newton 2007]) was significantly lower in areas with relatively higher trail density and off-road vehicle (ORV) traffic compared to areas with fewer trails or less ORV traffic. In a follow-up study, Spaul and Heath (2016) found several reasons for the patterns shown in Steenhof et al. (2014). Eagles were less likely to occupy nesting territories with more ORV traffic compared to nesting territories with less ORV traffic. At occupied territories, pedestrian and other non-motorized traffic were negatively associated with the probability an eagle pair laid eggs. At territories where eagles laid eggs, nest survival was negatively associated with shortterm peaks in ORV traffic. Finally, adult nest attendance during the incubation and broodrearing periods, an important predictor of nest survival, was negatively associated with pedestrian use (Spaul and Heath 2016). Studies of other eagle species suggest type of human activity, season, and proximity may all influence the flushing probability and distance at which flushing occurs (Grubb and King 1991, Steidl and Anthony 1996, Gonazáles et al. 2006). Taken together, these results suggest that disturbance from several forms of recreation may have cumulative effects that result in decreased eagle productivity and suggest that recreation management is an important component of travel management and eagle conservation plans which should be taken into consideration when determining compliance with the BGEPA.

To our knowledge, no published data exist regarding the factors influencing flushing probability or flushing distances in Golden Eagles. This paucity of data makes activity-specific management difficult and hinders the ability to set buffer distances supported by empirical evidence. We investigated whether the probability of flushing was affected by the type of recreationist, distance to encounter, eagle nest attendance, or date. We assessed whether recreation type, eagle nest attendance, or date predicted flushing distances of eagles. We evaluated factors that affected probability of flushing to understand factors predicting responses to human encounters and flushing distance, and to inform decisions about potential buffers.

\section{METHODS}

We monitored 23 nesting territories of Golden Eagles from 15 January to 6 July 2013 and 2014 on lands managed by the Bureau of Land Management's Owyhee Field Office (OFO) in southwestern Idaho. This time period was selected to assess eagle responses during the full length of the breeding season, from courtship and nest site 


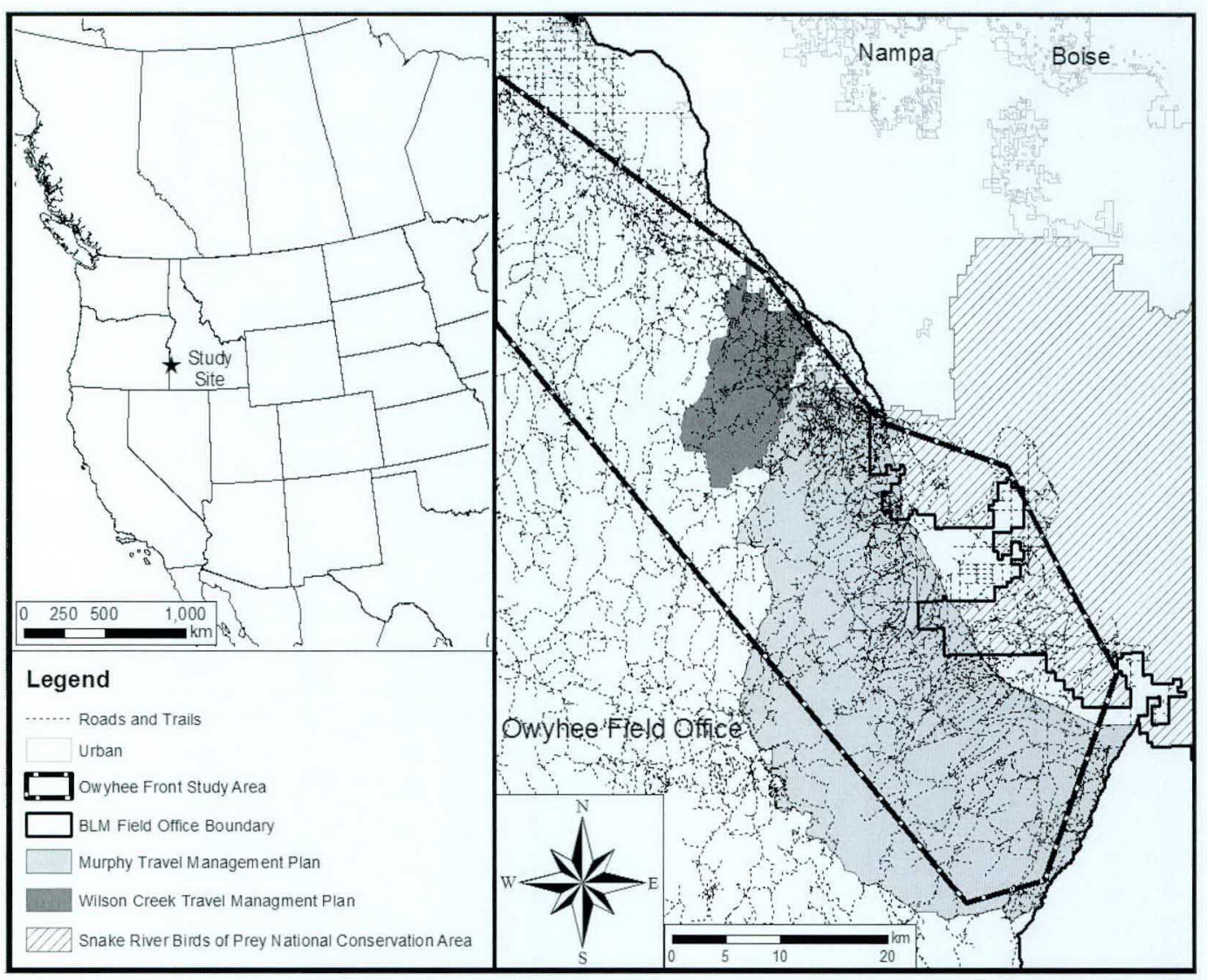

FIG. 1. Owyhee Front in southwest Idaho. Golden Eagle and recreation study site showing roads and trails, eagle territories studied, and travel management areas in the study area.

selection, through brood-rearing and fledging. Territories differed in the amount and type of recreation activity and were in a variety of travel management units, including the Morley Nelson Snake River Birds of Prey National Conservation Area (NCA), the Murphy Travel Management Plan (TMP), the Wilson Creek TMP, and areas without specific travel management designations (Fig. 1; BLM 2009). Our study area included territories exposed to predominantly ORV use $(n=5$, Murphy TMP and undesignated areas), predominantly non-motorized use ( $n=6$, Wilson Creek TMP and undesignated areas), areas with mostly road vehicle traffic ( $n=5$, NCA and Murphy TMP), and areas with little recreation ( $n=7$, Wilson Creek TMP and undesignated areas), but recreation type varied across all territories, and these classifications were not used in analyses. All territories were located in a sagebrush-dominated (Artemisia tridentata), heterogeneous shrub-steppe community in cliff-nesting habitat along the northern front of the Owyhee Mountains and south of the Snake River.

Nesting territories (per Steenhof and Newton 2007) were surveyed for occupancy and nest initiation from 15 January to 1 April (Steenhof and Newton 2007, Pagel et al. 2010). Observations of eagles on nests and perched in their territories were made from observation points located $600-1,200$ $\mathrm{m}$ away from nests to minimize the potential for researcher disturbance (Steidl et al. 1993, Gonzalez et al. 2006, Pagel et al. 2010) and were made from a truck or pop-up hunting blind. We observed eagles approximately every 30 days from 15 January through 6 July, on both weekend and mid-week days because recreation volume was higher on weekends than weekdays (Spaul and Heath 2016). We report mean egg-laying date for breeding territories, mean hatching date for territories where nestlings hatched, and mean 
TABLE 1. Summary of the different categories of recreationists passing Golden Eagles, number, mean distance and range of passes, and number of flushing responses induced when eagles were at nests and away from nests. Number of territories where flushes occurred are displayed in parentheses following the number of flushes.

\begin{tabular}{lccccc}
\hline \multicolumn{1}{c}{ Recreationist category } & $\begin{array}{c}\text { Number of } \\
\text { eagle passes }\end{array}$ & $\begin{array}{c}\text { Mean (SD) of } \\
\text { passes (m) }\end{array}$ & $\begin{array}{c}\text { Range of } \\
\text { passes (m) }\end{array}$ & $\begin{array}{c}\text { Number of flushing } \\
\text { responses at nests }\end{array}$ & $\begin{array}{c}\text { Number of flushing responses } \\
\text { away from nests }\end{array}$ \\
\hline Non-motorized riders & 14 & $582(319)$ & $400-1,100$ & 0 & 0 \\
Pedestrians & 11 & $779(313)$ & $200-1,300$ & 0 & $1(1)$ \\
Off-road vehicles & 121 & $414(254)$ & $90-1,300$ & $6(5)$ & $11(8)$ \\
Road vehicles & 107 & $553(276)$ & $30-1,100$ & $2(2)$ & $5(4)$ \\
Mixed & 17 & $707(330)$ & $150-1,300$ & $5(3)$ & $6(5)$ \\
\hline
\end{tabular}

fledging date for all successful breeding territories, and the Julian day for each associated date, for reference purposes.

During 4-hr behavioral observations, we identified and tallied all-terrain vehicles (ATVs), rock crawler/utility-terrain vehicles (UTVs), dirt bikes, truck or sport-utility vehicles (SUVs), passenger vehicles, mountain bikers, horseback riders, and pedestrians within $1,200 \mathrm{~m}$ of nests. Measurements establishing the distance of recreationists from nests were based on a GIS database containing all trails within the study site (BLM-OFO, unpubl. data) and all eagle nests. We recorded the position of all perched eagles in the field using GPS units (GPSmap 62stc, Garmin International Inc., Olathe, KS, USA), and used these points to estimate distances between recreationists and eagles. In almost all instances $(98.2 \%)$ of recreationists passing within $1,200 \mathrm{~m}$ of an eagle, the recreationist remained on a designated trail, however, five did not; in those cases, their location was plotted in the field using a GPS unit. If a recreationist passed an eagle within $1,200 \mathrm{~m}$, but was $>1,200 \mathrm{~m}$ from a nest, we determined the closest distance they passed to the eagle. Trails meandered through eagle territories and relative to eagle locations so that the approaches of recreationists towards eagles were dynamic, changing from direct to tangential and vice versa. Because of the diverse topography of the landscape and differences in detecting motorized and non-motorized recreationists, starting distances of recreationists were not recorded nor were the total times that recreationists spent within 1,200 m of the eagle or nest. We recorded whether an eagle flushed and estimated distance based on the location of the recreationist along the trail relative to the location of the perched or nesting eagle. If an eagle flushed from a nest, we continued observations and noted how long it took before the eagle returned to the nest and resumed pre-disturbance activity. Golden Eagles are not sexually dimorphic by plumage; while we were able to infer sex of eagles by incubation time (Collopy 1984) or copulation behavior, this wasn't reliable enough to use in determining differences between male and female eagles' responses.

We categorized recreationists based on the presence or absence of motors, common trail use patterns, and activities in the presence of eagles as: 1) ORVs (all ATVs, rock crawlers, UTVs, and dirt bikes) had motors and usually, but not always, used trails, 2) road vehicles (all SUVs, trucks, and passenger vehicles) had motors and stayed on trails, 3) non-motorized riders (horseback riders and mountain bikers) usually stayed on trails, 4) pedestrians were not associated with a vehicle and sometimes went off trail, and 5) mixed recreationists were motorized recreationists (ORVs or road vehicles) that stopped and became pedestrians within 1,200 $\mathrm{m}$ of an eagle. Motorized recreationists that stopped, but did not exit or step off their vehicle before continuing, were categorized in their respective motorized category.

Eagles did not flush in response to nonmotorized riders, and only flushed once in response to a pedestrian (Table 1), so these types of encounters were removed from analyses of flushing probability and distance. The final dataset used in inferential analyses included 245 instances of an ORV, road vehicle, or mixed recreationist passing an eagle. We used a generalized linear mixed model (GLMM) with a binomial distribution, log link, and territory identity as a random effect to assess whether eagle flushing was explained by any of four predictor variables: 1) At_Nest, whether an eagle was on a nest or not, 2) Rec_Dist_to_Bird, the distance between the eagle 


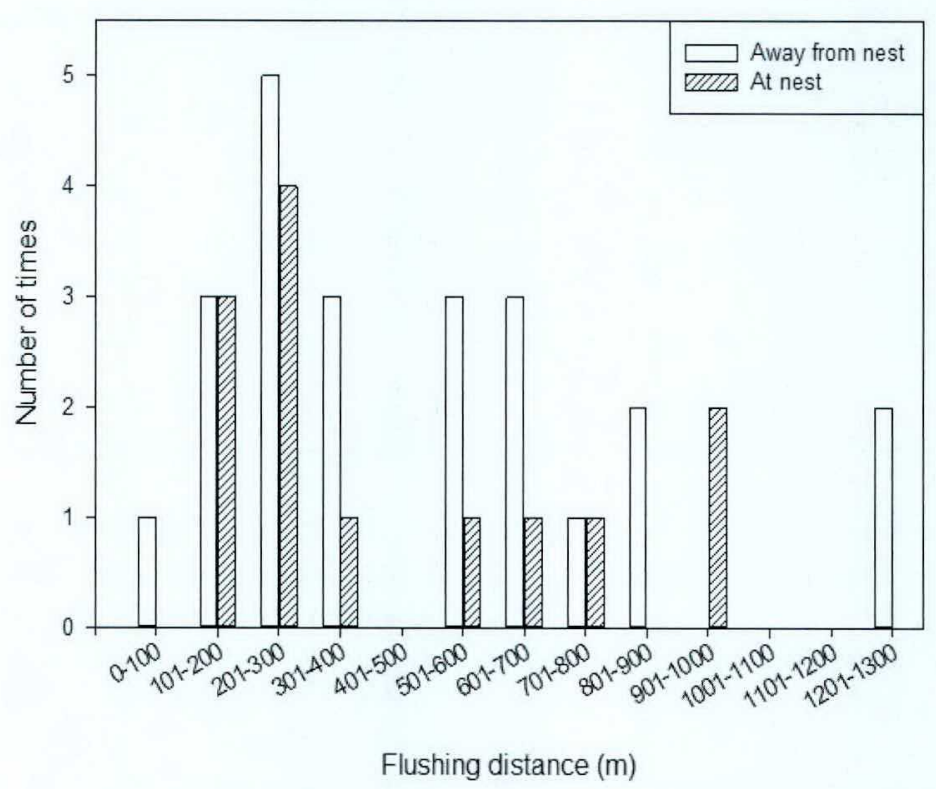

FIG. 2. Flushing distances of Golden Eagles at nests $(n=13)$ and on perches away from nests $(n=23)$ in response to recreationists in southwestern Idaho in 2013 and 2014.

and the recreationist, 3) Rec_Category, the category of recreationist (ORV, road vehicle, or mixed), and 4) Julian_Date. We used a linear mixed model (LMM) with territory identity as a random effect to assess whether 1) At_Nest, 2) Rec_Category, or 3) Julian_Date affected flushing distances of eagles (package lme4, R 3.1.1). The random variable territory identity was used to account for the fact that we could not identify individual eagles, and it is likely that we had repeated observations on the same bird. We checked residuals plots to ensure that the data fit model assumptions. We used a modified stepwise and information theoretic model selection approach (Burnham and Anderson 2002) to assess whether the predictor variables explained flushing or flushing distance. We used AICc to compare single variable models first, and then created and assessed multivariate models using single variables that out-performed an intercept-only model and had a $\triangle \mathrm{AICc}<6$ (Burnham et al. 2011). We considered all models in the final candidate set with $\triangle \mathrm{AICc}<6$ that did not contain uninformative parameters (Arnold 2010) to be useful for inference. We estimated $85 \%$ confidence intervals for parameters to be compatible with an AIC approach (Arnold 2010). Approximate marginal (fixed effect) and conditional (random and fixed effects) variance $\left(R^{2}\right)$ are reported for all models based on Nakagawa and Schielzeth (2013).

\section{RESULTS}

During 212 (mean of 4.7 per territory, SD $=1.1$ ) 4-hr behavioral observations (mean of $3.87, \mathrm{SD}=$ $0.6 \mathrm{hr}$ ) totaling $820 \mathrm{hrs}$, we observed 812 recreationists and road vehicles pass through eagle nesting territories, and fifteen $(1.8 \%)$ of these recreationists went off trail. Of the off-trail recreationists, the majority were pedestrians or mixed recreationists $(66.7 \%)$, and some were ORVs $(20 \%)$ or non-motorized riders $(13.3 \%)$. On 270 occasions, recreationists passed either a perched $(n$ $=87)$ or nesting $(n=183)$ eagle at 15 territories in 2013 and 19 territories in 2014. Recreationists passed eagles at a mean of $511 \pm 291 \mathrm{~m}$ (SD) $($ range $=30-1,300 \mathrm{~m})$, a mean of $7.9 \pm 10.0(\mathrm{SD})$ times per territory (range $=1-38$ ). In most cases $(86 \%)$, eagles did not flush in response to encounters with recreationists (Table 1). We observed 36 flushing events (13 by eagles at nests, 23 by eagles on perches) in response to recreation activities at distances that ranged from 300 to 1,300 $\mathrm{m}$ from eagles (Fig. 2). We observed eagles flushing in response to recreationists at 15 of the 23 nesting territories, with more than one flushing event 
TABLE 2. AICc table showing candidate models, number of parameters $(K)$, delta AICc ( $\triangle \mathrm{AICc})$, AICc weights (AICc Wt.), marginal variance $\left[R^{2}(\mathrm{~m})\right]$, and conditional variance $\left[R^{2}(\mathrm{c})\right]$ for models used to explain the probability of a Golden Eagle flushing in response to a passing recreationist $(n=245)$ in southwestern Idaho in 2013 and 2014. At_Nest is a categorical variable that indicates whether an eagle was at a nest or perched away from a nest. Rec_Cat is a categorical variable describing the three categories of recreation activity assessed: 1) ORVs (all ATVs, UTVs, and dirt bikes), 2) road vehicles (all SUVs, trucks, and passenger vehicles) and 3) mixed (motorized recreationists who stopped and became pedestrians). Rec_Dist to_Bird is a continuous variable, measuring the closest distance between the recreation activity and the eagle. All models included the random variable for territory identity.

\begin{tabular}{lccccc}
\hline \multicolumn{1}{c}{ Model } & $K$ & $\Delta \mathrm{AICc}$ & AlCc Wt. & $R^{2}(\mathrm{~m})$ & $R^{2}(\mathrm{c})$ \\
\hline Rec_Cat + At_Nest ${ }^{\mathrm{a}}$ & 5 & 0.00 & 0.85 & 0.34 & 0.60 \\
Rec_Cat + At_Nest + Rec_Cat X At_Nest & 7 & 3.46 & 0.15 & 0.35 & 0.62 \\
Rec_Cat & 4 & 14.45 & 0.00 & 0.18 & 0.49 \\
At_Nest & 3 & 18.55 & 0.00 & 0.18 & 0.55 \\
Rec_Dist_to_Bird & 3 & 33.36 & 0.00 & 0.03 & 0.54 \\
Intercept & 2 & 33.86 & 0.00 & 0.000 & 0.45 \\
Julian_Date & 3 & 35.91 & 0.00 & 0.000 & 0.05 \\
\hline
\end{tabular}

${ }^{\mathrm{a}} \mathrm{AICc}=159.94$.

occurring at 11 of the territories. Flush responses were elicited by all recreation types, except nonmotorized riders (Table 1). Mean egg-laying date in our study area was 5 March $(n=21$, Julian Date $=$ $64 \pm 6$ days [SD], Julian Date $=65$ and 63, in 2013 and 2014, respectively). Mean hatching date was 16 April ( $n=19$, Julian Date $=106 \pm 6$ days [SD]). Mean fledging date was 24 June $(n=8$, Julian Date $=175 \pm 9$ days [SD]).

A model with recreationist category $(\beta=4.1, \mathrm{CI}$ $=2.8-5.7$, for mixed recreationists, $\beta=1.5, \mathrm{CI}=$ $0.5-2.7$, for ORVs) and whether an eagle was at a nest $(\beta=-2.5, \mathrm{CI}=-3.6-1.6)$ was the bestsupported model for explaining flushing probability (Table 2). The marginal and conditional $R^{2}$ for the top model were 0.352 and 0.602 , respectively, suggesting good model fit, but substantial variation in flushing probability which remains unexplained by recreationist category or whether an eagle was at a nest. Eagles were 60 times more likely to flush in response to motorized recreationists stopping and transitioning to walking (11 of 17 passes), and 4.5 times more likely to flush in response to offroad vehicle (ORV) riders (17 of 121 passes) than during encounters with road vehicles (7 of 107 passes) (Fig. 3). Eagles were 12 times more likely to flush when perched away from nests ( 23 of 87 passes) than when at nests (13 of 183 passes). Distance to recreationist and date did not help explain the probability of flushing (Table 2).

Top models for explaining flushing distance included either recreationist category and/or date or interactions between recreationist category and date (Table 3). In general, flushing distances were longer earlier in the year and shorter later in the nesting season (Fig. 4), and flushing distances were longer for mixed recreationists than for ORVs and road vehicles (Fig. 4). Golden Eagles flushed at greater distances in response to motorized recreationists that transitioned to walking (lsmean $=620 \mathrm{~m}, \mathrm{SE}=96$ ) than when responding to either ORV riders (lsmean $=525 \mathrm{~m}$, $\mathrm{SE}=90)$ or road vehicles (1smean $=318 \mathrm{~m}, \mathrm{SE}=$ 120). The effect of date tended to depend on recreation category, with the greatest declining temporal trends for mixed recreationists (CI: -6.8 to -1.8; Fig. 4), and trends that declined, but with confidence intervals that overlapped zero, for ORV riders (CI: $-5.1-1.6)$ and road vehicles (CI: $-2.7-$ 1.9). The marginal and conditional $R^{2}$ for the model with the best overall fit to the data (a model including recreationist category, Julian Date, and an interaction between them) were 0.18 and 0.90 , respectively, suggesting good model fit but substantial variation in flushing distance between territories.

Of 13 instances where eagles flushed from nests, nests with eggs or young were left unattended 10 times and eagles flushed from nests before egglaying three times. Time away from nests, where eggs or nestlings were exposed (mean $=57.2 \pm$ 86.8 [SD] min), showed a bimodal pattern, with seven eagles spending $<40$ mins away from nests $(\min .=3.9$ mins $)$ and three spending $>90 \mathrm{~min}$ away from nests (max. $=286$ mins). Because of small sample sizes of flushing, we did not model 


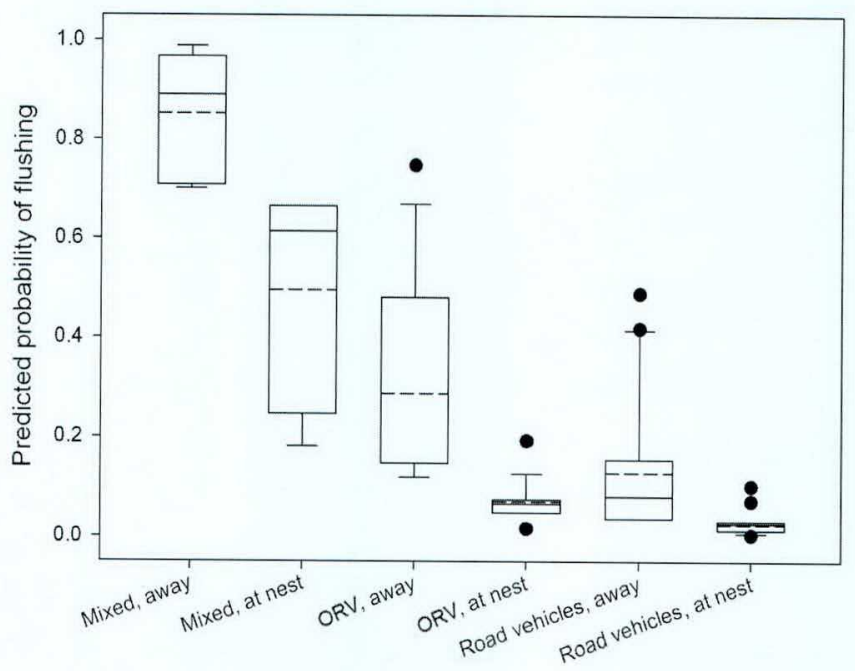

FIG. 3. Model estimated probability of flushing by each recreation category and whether the eagle was at a nest (incubating, brooding, feeding, perched at the nest, or engaged in nest maintenance) or away from a nest (perched). Box plots are $25-75 \%$ quartiles and bars mark $95-5 \%$ intervals of predicted probability of flushing. Medians are solid black line, means are dashed line, and dots are observations outside the central $95 \%$ intervals.

the influence of recreation type or other effects on this time. Flushes by road vehicles $(n=2)$ caused eagles to be away from nests for a mean of 148.4 mins $(\mathrm{SD}=194.9$, range $=10.6-286)$, mixed recreationists $(n=3)$ caused a mean of $71.2 \mathrm{mins}$ away from the nest $(\mathrm{SD}=34.4$, range $=31.6-$ 92.2), and ORVs $(n=5)$ caused a mean of 12.23 mins away from the nest $(\mathrm{SD}=7.0$, range 3.9-22).

\section{DISCUSSION}

Golden Eagles in our study were most likely to flush in response to motorized recreationists who stopped and became pedestrians (mixed recreationists), and did so at greater distances than eagles responding to ORVs and road vehicles. Golden Eagles did not flush in response to most $(86 \%)$ recreationists, especially those that continued passing eagles in a continuous manner. Similarly, Steidl and Anthony (1996) reported relatively low rates of flushing (23\%) by breeding Bald Eagles in response to steadily moving passes by nonmotorized watercraft, even though they were much closer passes than in our study. These data suggest that eagles in our study area may be somewhat habituated to recreationists that do not change their behavior. Eagles may perceive mixed recreationists as a greater threat either because of their unpredictable transitions between activities (McGarigal et al. 1991) or their propensity to leave travel corridors and directly approach avian

TABLE 3. AICc table showing candidate models, number of parameters $(K)$, delta AICc ( $\triangle \mathrm{AICc}$ ), AICc weights (AICc Wt.), marginal variance $\left[R^{2}(\mathrm{~m})\right]$, and conditional variance $\left[R^{2}(\mathrm{c})\right]$ for models used to explain flushing distance of Golden Eagles $(n=35)$, in response to passing recreationists in southwestern Idaho in 2013 and 2014. Julian_Date is day of year, Rec_Cat and At_Nest as in Table 1; all models included a random variable for territory identity.

\begin{tabular}{lccccc}
\hline \multicolumn{1}{c}{ Model } & $\kappa$ & AAICc & AICc Wt. & $R^{2}(\mathrm{~m})$ & $R^{2}(\mathrm{c})$ \\
\hline Julian_Date $^{\mathrm{a}}$ & 4 & 0.00 & 0.29 & 0.10 & 0.80 \\
Rec_Cat + Julian_Date & 6 & 0.27 & 0.25 & 0.17 & 0.84 \\
Rec_Cat + Julian_Date + Rec_Cat X Julian_Date & 8 & 1.03 & 0.17 & 0.18 & 0.90 \\
Rec_Category & 5 & 1.07 & 0.17 & 0.11 & 0.85 \\
Intercept & 3 & 2.16 & 0.10 & 0.000 & 0.78 \\
At_Nest & 4 & 4.42 & 0.03 & 0.005 & 0.78 \\
\hline
\end{tabular}

\footnotetext{
${ }^{a} \mathrm{AICc}=494.97$
} 


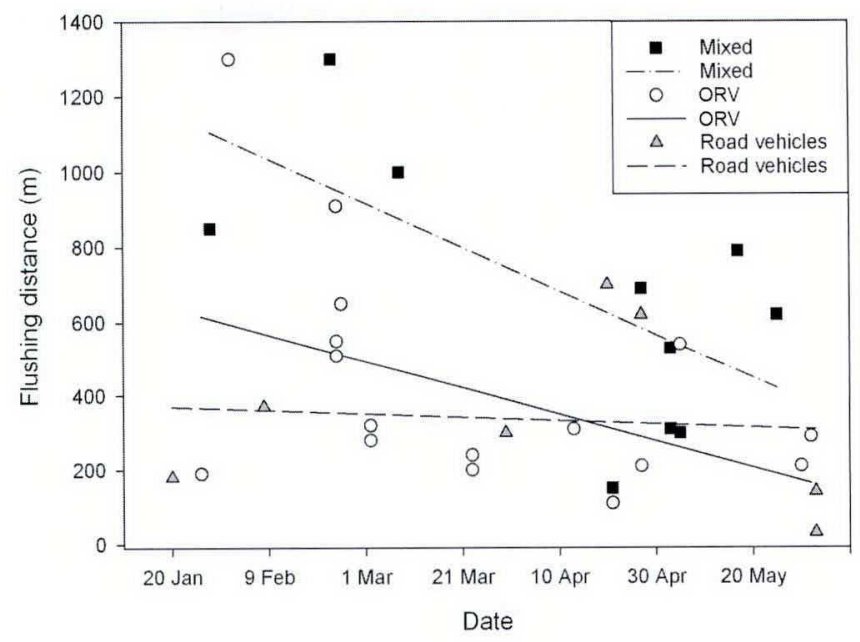

FIG. 4. Effect of date and recreation category on observed (symbols) and predicted (lines) flushing distances of Golden Eagles. Mixed refers to motorized recreationists that stopped and became a pedestrian, ORVs included all-terrain vehicles (ATVs), utility-terrain vehicles (UTVs), rock crawlers, and dirt bikes, and road vehicles, included all trucks, sport-utility vehicles (SUVs), and passenger vehicles.

species (Klein 1993). ORVs and trucks rarely went off trails and generally passed through eagle territories in a few minutes. However, most pedestrians arrived in eagle territories via road vehicles or ORVs and frequently went off trails and then meandered, lingered in an area, or even directly approached eagles. Eagles and other avian taxa may perceive continuously moving motorized vehicles as less threatening than those that stop and transition to pedestrian activities, possibly because pedestrians engage in persecution ( $\mathrm{Ga}$ leotti et al. 2000).

González et al. (2006) found that an increase in human activity, and the subsequent increase in flushing events, caused decreased hatching success in Spanish Imperial Eagles (Aquila adalberti). That study found that nearby pedestrian disturbance caused more flight responses than vehicles, possibly because of the patterns of their movements and prolonged visits to eagle territories (González et al. 2006). The pedestrians most likely to cause Spanish Imperial Eagles to flush were hunters (people with firearms and dogs) and ecotourists (people slowly bird-watching, Gonzalez et al. 2006) that may have been likely to behave similarly to the mixed recreationists in our study that often moved slowly. González et al. (2006) did not distinguish between pedestrians that disembarked from a vehicle near eagles and pedestrians that entered eagle territories on foot, so it is difficult to directly compare the effect of those pedestrians to the pedestrians and mixed recreationists in this study. In addition to activity patterns, González et al. (2006) attributed different responses to different types of recreationists, in part, to a history of lethal and non-lethal persecution from illegal shooting. Within our study area there are 53 shooting areas, and the mean distance to the nearest shooting spot from the centroid of eagle territories was $1,829 \mathrm{~m} \pm$ 1,614 [SD] (RJS, unpubl. data). Although we saw no evidence of persecution, illegal shooting continues to threaten Golden Eagles (Russel and Franson 2014), and some eagles in our study may have had previous encounters that affected their avoidance behavior and flushing distance.

Golden Eagles were more likely to flush when perched away from nests than when at nests. Previous studies suggest this trend occurs in many avian taxa (Livezey et al. 2016), and our results are consistent with Bald Eagles in Arizona and Alaska that were less likely to flush at the nest than away from the nest (Grubb and King 1991, Steidl and Anthony 1996). It is possible that this occurs because of differences in responsiveness between males and females, but as we were unable to determine and analyze the potential effect of sex on flushing probability, this area may need further 
research in Golden Eagles. Reduced likelihood of flushing at nests may be explained by the higher cost of flushing from nests compared to perch sites. Unattended nests have a higher probability of nest failure for many bird species (Clark and Ydenberg 1990), including Golden Eagles (Spaul and Heath 2016). Additionally, avian species may be less likely to flush from nests than perches to avoid disclosing nest locations to perceived predators (Albrecht and Klvaňa 2004).

We found that eagles on nests and perches flushed at greater distances early in the breeding season, particularly in response to mixed recreationists, suggesting that eagles were more responsive to disturbance early in the breeding season than later. Fraser et al. (1985) also found decreasing flushing distances for Bald Eagles at the nest as the breeding cycle progressed. Watson (2010) noted that Golden Eagles were more likely to abandon nesting attempts in response to disturbance during nest initiation and egg-laying than during incubation and brood-rearing. Early season, disturbance-based nest failure has been attributed to the susceptibility of eggs to exposure (Fremming 1980); however, seasonal changes in adult responsiveness may contribute to this pattern. Changes in tolerance of disturbance may be related to seasonal changes in hormones that facilitate parental care and life-history decisions (Angelier et al. 2016) or changes in parental investment as the egg and young age (Galeotti et al. 2000).

We found that seasonal changes in flushing distances were more apparent for mixed recreationists, suggesting that a combination of perceived risk in pedestrian activities, combined with temporally increasing investment by breeding eagles, makes them most susceptible to such activity early in the breeding cycle. The less significant effect of this for road vehicles and ORVs, when interacting with date, further suggests a reduced perception of threat by these activities compared to the greater threat posed by mixed recreationists.

Three eagles in our study flushed from nests where no adult returned to the nest for more than 90 mins ( $\max .=248$ mins), long enough to potentially contribute to reproductive failure because of reduced egg viability (Driscoll et al. 1999), heat exposure (Beecham and Kochert 1975) or increased predation risk (Stien and Ims 2016).
At one of these three nests, where the flushed eagle was feeding a nestling, that nestling subsequently died, though it is unclear whether this disturbance was the direct cause of nest failure. Flushing in response to recreationists is consistent with a negative association between Golden Eagles' nest attendance and pedestrian activity, which could lead to reduced nest survival (Spaul and Heath 2016) or reduced productivity associated with recreation (Steenhof et al. 2014). Further, consistent effects across several types of responses, related to risk avoidance and reproduction, suggest that recreationists that transition from motorized to pedestrian activities elicited responses that could lead to population-level effects and demonstrates the utility of using flushing behavior as an index of disturbance effects.

Because we selected observation points on each eagle territory to minimize investigator disturbance, our visibility was sometimes constrained by topography, preventing collection of data on starting distance (Blumstein 2003). Similarly, because of the location of roads and trails relative to perches and nest sites in our study, the distance at which eagles first detected recreationists was likely variable in our study. Controlling for such biases and potential error is difficult for large, highly visual species like eagles (González et al. 2006), but efforts to do so would be useful for managers who need to consider the effects of local topography and trail proximity to nesting and perching sites when managing recreation in eagle territories.

Buffer zones (or setback distances) and seasonal restrictions on human activities near key wildlife habitat are common management strategies used to reduce or eliminate the negative effects of disturbance on wildlife reproduction (Rodgers and Schwikert 2002, Fernández-Juricic et al. 2005, Burger et al. 2010), and are often used around raptor nests (Knight and Gutzwiller 1995, Brambilla et al. 2004, Klute 2008). To prevent the potential for take as a result of disturbance under the BGEPA, a buffer zone of $650 \mathrm{~m}$ around nests of Golden Eagles in our study area may have prevented $77 \%$ of flushes from nests, and a 1,000 $\mathrm{m}$ buffer may have prevented $100 \%$ of flushes from nests (Fig. 2). Because flushing distances were greater earlier in the nesting season (Fig. 4) and eagles are more susceptible to nest-site disturbance during nest initiation, a buffer zone 
$>650 \mathrm{~m}$ may be prudent. Establishing nest-site buffer zones would be especially beneficial during the early portion of the nesting season. However, if buffer areas are nest-site focused, public land managers must consider annual variation in the location of eagle nest sites in the same nesting territories (Kochert and Steenhof 2012, Millsap et al. 2015, Slater et al. 2017). This would require annual monitoring and buffer implementation for all managed territories or perhaps larger, long-term buffer areas based on a nest centroid in territories of Golden Eagles. Focusing management efforts only on nest-site protection means that other aspects of daily behavior may still be affected. For example, if displaced from key hunting areas, the ability of Golden Eagles to forage effectively and provide for an incubating mate or nestlings may be negatively affected. The increased likelihood of eagles flushing when perched away from nests suggests that recreation disturbance occurs throughout eagle territories and not just at nest sites (Tarjuelo et al. 2015). However, in the current framework of the BGEPA, and without further study, it is unclear whether such perch associated flushing contributes to reproductive failure.

Setting permanent trail closures, establishing buffer zones, and implementing seasonal restrictions of trail use may be effective strategies for managing recreation around eagle nests, but such policies will likely be controversial in some highuse recreation areas. The inherent value and longterm sustainability of any conservation initiative directed towards management of Golden Eagles on public lands will be most successful with public support. One option for achieving this may be the implementation of "no-stopping" zones where offroad recreation is permitted, but recreationists are asked to continue moving during the eagle breeding season. Signage could be placed at the beginning of trails that pass within $650 \mathrm{~m}$ (or $1,000 \mathrm{~m}$ ) of eagle nests, and in a way that does not explicitly reveal the location of nests. A combination of management strategies, such as trail closures, no-stopping zones, increased enforcement of existing trail regulations, limiting expansion of new trails, and management that considers the entire eagle territory and the full duration of eagle breeding seasons, would help reduce negative human-eagle interactions.

\section{ACKNOWLEDGMENTS}

We are indebted to J. Sutter, K. Steenhof, J. Barber, and $\mathrm{M}$. Kochert, for advice in designing this project and sharing research experience. We thank C. Davis, J. Roelke, L. Eberhart-Phillips, N. Paprocki, and J. Sherburne for help in the field. We appreciate B. Jost, R. Homan, and C. Braun of the BLM's Owyhee Field Office for logistical support and insight into public land management, and M. Stuber, K. Powell and B. Woodbridge of the USFWS for research support. Special thanks to all the members of the Heath Lab for their technical support.

This project was supported by the Idaho BLM Challenge Cost Share Grant, a grant from the USFWS, the USFWS Western Golden Eagle Team, the Idaho EPSCoR National Science Foundation (NSF) Award \# IIA-1301792, and the Raptor Research Center at Boise State University. None of the funders had any influence on the content of the submitted or published manuscript. None of the funders required approval of the final manuscript to be published. No IACUC protocol was required because this was an observation-based study. We thank J. Jorgensen, G. Ritchison, and three anonymous reviewers for comments that improved earlier versions of the manuscript.

\section{LITERATURE CITED}

Albrecht, T. and P. Klvaña. 2004. Nest crypsis, reproductive value of a clutch and escape decisions in incubating female Mallards Anas platyrhynchos. Ethology 110:603-613.

Angelier, F., J. C. Wingfield, S. Tartu, and O. Chastel. 2016. Does prolactin mediate parental and life-history decisions in response to environmental conditions in birds? A review. Hormones and Behavior 77:18-29.

ARNold, T. W. 2010. Uninformative parameters and model selection using Akaike's Information Criterion. Journal of Wildlife Management 74:1175-1178. doi:10.2193/ 2009-367

Beecham, J. J. And M. N. Kochert. 1975. Breeding biology of the Golden Eagle in southwestern Idaho. Wilson Bulletin 87:506-513.

Blumstein, D. T. 2003. Flight-initiation distance in birds is dependent on intruder starting distance. Journal of Wildlife Management 67:852-857.

Brambilla, M., D. Rubolini, and F. Guidali. 2004. Rock climbing and raven (Corvus corax) occurrence depress breeding success of cliff-nesting peregrines (Falco peregrinus). Ardeola 51:425-430.

Brown, C. L., A. R. Hardy, J. R. Barber, K. M. Fristrup, K. R. Crooks, and L. M. Angeloni. 2012. The effect of human activities and their associated noise on ungulate behavior. PLoS One. 7:1-9.

Buick, A. M. AND D. C. PAton. 1989. Impact of off-road vehicles on the nesting success of Hooded Plovers Charadrius rubricollis in the Coorong region of South Australia. Emu 89:159-172.

Bureau of Land Management (BLM). 2009. Environmental assessment: Murphy subregion travel management plan. USDI, Bureau of Land Management, Environmental Assessment ID-130-2007-EA-3431. Owyhee Field Office, Marsing, Idaho, USA. 
Burger, J., M. Gochfeld, C. D. Jenkins, and F. Lesser. 2010. Effect of approaching boats on nesting Black Skimmers: using response distances to establish protective buffer zones. Journal of Wildlife Management 74:102-108.

Burnham, K. P. And D. R. Anderson. 2002. Model selection and multimodel inference: a practical informationtheoretic approach. Second Edition. Springer-Verlag, New York, USA.

Burnham, K. P., D. R. Anderson, and K. P. Huyvaert. 2011. AIC model selection and multimodel inference in behavioral ecology: some background, observations, and comparisons. Behavioral Ecology and Sociobiology 65:23-35.

Clark, C. W. and R. C. Ydenberg. 1990. The risks of parenthood. I. General theory and applications. Evolutionary Ecology 4:21-34.

Collopy, M. W. 1984. Parental care and feeding ecology of Golden Eagle nestlings. Auk 101:753-760.

Costello, C. M., S. I. Cain, R. M. Nielson, C. Servheen, AND C. C. Schwartz. 2013. Response of American black bears to the non-motorized expansion of a road in Grand Teton National Park. Ursus 24:54-69.

De Jong, A., C. Magnhagen, and C.-G. Thulin. 2013. Variable flight initiation distance in incubating Eurasian Curlew. Behavioral Ecology and Sociobiology 67:1089-1096.

Driscoll, D. E., R. E. Jackman, W. G. Hunt, G. L. Beatty, J. T. Driscoll, R. L. Glinski, T. A. Gatz, and R. I. MestA. 1999. Status of nesting Bald Eagles in Arizona. Journal of Raptor Research 33:218-226.

Fernández, C. and P. Azkona. 1993. Human disturbance affects parental care of marsh harriers and nutritional status of nestlings. Journal of Wildlife Management 57:602-608.

Fernández-Juricic, E. And J. L. Telleria. 2000. Effects of human disturbance on spatial and temporal feeding patterns of blackbird Turdus merula in urban parks in Madrid, Spain. Bird Study 47:13-21.

Fernández-Juricic, E., M. P. Venier, D. Renison, and D. T. BlumsteIn. 2005. Sensitivity of wildlife to spatial patterns of recreationist behavior: a critical assessment of minimum approaching distances and buffer areas for grassland birds. Biological Conservation 125:225-235.

Finney, S. K., J. W. Pearce-Higgins, and D. W. Yalden. 2005. The effect of recreational disturbance on an upland breeding bird, the golden plover Pluvialis apricaria. Biological Conservation 121:53-63.

Fraser, J. D., L. D. Frenzel, and J. E. Mathisen. 1985. The impact of human activities on breeding Bald Eagles in north-central Minnesota. Journal of Wildlife Management 49:585-592.

Fremming, O. R. 1980. Kongeørn i Norge. Viltrapport 12:163.

Frid, A. AND L. DiLl. 2002. Human-caused disturbance stimuli as a form of predation risk. Conservation Ecology 6(1):11.

Galeotti, P., G. Tavecchia, and A. Bonetti. 2000. Parental defence in Long-eared Owls Asio otus: effects of breeding stage, parent sex and human persecution. Journal of Avian Biology 31:431-440.
Gill, J. A. and W. J. Sutherland. 2000. Predicting the consequences of human disturbance from behavioural decisions. Pages 51-64 in Behaviour and conservation. Gosling, L. M. and W. J. Sutherland (Editors) Cambridge University Press, Cambridge, United Kingdom.

Gonzalez, L. M., B. E. Arroyo, A. Margalida, R. Sánchez, AND J. ORIA. 2006. Effect of human activities on the behaviour of breeding Spanish Imperial Eagles (Aquila adalberti): management implications for the conservation of a threatened species. Animal Conservation 9:85-93.

GrubB, T. G. And R. M. King. 1991. Assessing human disturbance of breeding Bald Eagles with classification tree models. Journal of Wildlife Management 55:500 511.

Harris G., R.M. Nielson, T. Rinaldi, and T. Lohuis. 2014. Effects of winter recreation on northern ungulates with a focus on moose (Alces alces) and snowmobiles. European Journal of Wildlife Resources 60:45-58.

Hayward, L. S., A. E. Bowles, J. C. Ha, and S. K. Wasser. 2011. Impacts of acute and long-term vehicle exposure on physiology and reproductive success of the Northern Spotted Owl. Ecosphere 2:65.

Kight, C. R. and J. P. Swaddle. 2007. Associations of anthropogenic activity and disturbance with fitness metrics of Eastern Bluebirds (Sialia sialis). Biological Conservation 138:189-197.

KLeIN, M. L. 1993. Waterbird behavioral responses to human disturbances. Wildlife Society Bulletin 21:3139

KLute, D. 2008. Recommended buffer zones and seasonal restrictions for Colorado raptors. Colorado Division of Wildlife, Denver, USA. cpw.state.co.us/Documents/ WildlifeSpecies/LivingWithWildlife/RaptorBufferGuidelines2008.pdf (accessed 14 Jan 2016).

Knight, R. L. AND K. J. GutZWiller (Editors). 1995. Wildlife and recreationists: coexistence through management and research. Island Press, Washington, D.C., USA.

Kochert, M. N. AND K. SteEnhof. 2012. Frequency of nest use by Golden Eagles in southwestern Idaho. Journal of Raptor Research 46:239-247.

Livezey, K. B., E. Fernández-Juricic, and D. T. Blumstein. 2016. Database of bird flight initiation distances to assist in estimating effects from human disturbance and delineating buffer areas. Journal of Fish and Wildlife Management 7:181-191.

Mason, J. T., C. J. W. McClure, and J. R. Barber. 2016. Anthropogenic noise impairs owl hunting behavior. Biological Conservation 199:29-32.

McGarigal, K., R. G. Anthony, and F. B. Isaacs. 1991. Interactions of humans and Bald Eagles on the Columbia River Estuary. Wildlife Monographs 115:147.

McGowan, C.P. And T.R. Simons. 2006. Effects of human recreation on the incubation behavior of American Oystercatchers. Wilson Journal of Ornithology 118:485-493.

McLeod, E.M., P-J. Guay, A. J. Taysom, R. W. Robinson, AND M. A. Weston. 2013. Buses, cars, bicycles and walkers: the influence of the type of human transport 
on the flight responses of waterbirds. PLoS ONE 8(12):e82008.

Millsap, B. A., T. G. Grubb, R. K. Murphy, T. Swem, and J. W. WATSON. 2015. Conservation significance of alternative nests of Golden Eagles. Global Ecology and Conservation 3:234-241.

Nakagawa, S. And H. Schielzeth. 2013. A general and simple method for obtaining $\mathrm{R}^{2}$ from generalized linear mixed-effects models. Methods in Ecology and Evolution 4:133-142.

Newsome, D., S. A. Moore, and R. K. Dowling. 2013. Natural area tourism: ecology, impacts and management. Second Edition. Channel View Publications, Tonawanda, New York, USA.

Pagel, J. E., D. M. Whittington, And G. T. Allen. 2010. Interim Golden Eagle technical guidance: inventory and monitoring protocols; and other recommendations in support of eagle management and permit issuance. USDI, Fish and Wildlife Service, Division of Migratory Bird Management, Falls Church, Virginia, USA. www. energy.ca.gov/sitingcases/palen/compliance/2013-0312 US Fish_and_Wildlife_Services_Interim_Golden Eagle_Technical_Guidance_-_Inventory_and Monitoring_Protocols_and_Other_Recommendations TN-69896.pdf (accessed 14 Jan 2016).

Palacios, E. and E. Mellink. 1996. Status of the Least Tern in the Gulf of California. Journal of Field Ornithology 67:48-58.

Pauli, B. P., R. J. Spaul, and J. A. Heath. 2017. Forecasting disturbance effects on wildlife: tolerance does not mitigate effects of increased recreation on wildlands. Animal Conservation 20:251-260. doi:10.1111/acv. 12308

Reed, S.E. And A.M Merenlender. 2008. Quiet, nonconsumptive recreation reduces protected area effectiveness. Conservation Letters 1:146-154.

Rodgers, J. A. AND S. T. Schwikert. 2002. Buffer-zone distances to protect foraging and loafing waterbirds from disturbance by personal watercraft and outboardpowered boats. Conservation Biology 16:216-224.

Romin, L. A. AND J. A. Muck. 2002. Utah Field Office guidelines for raptor protection from human and land use disturbances. USDI, Fish and Wildlife Service, Utah Field Office, Salt Lake City, USA. www.fws.gov/ utahfield office/Documents/MigBirds/Raptor\% 20Guidelines\%20(v\%20March\%2020,\%202002).pdf (accessed 24 Jan 2017).

Russel, R. E. and J. C. Franson. 2014. Causes of mortality in eagles submitted to the National Wildlife Health Center 1975-2013. Wildlife Society Bulletin 38:697704.

Slater, S. J., K. R. Keller, and R. N. Knight. 2017. Interannual Golden Eagle (Aquila chrysaetos) nest-use patterns in central Utah: implications for long-term nest protection. Journal of Raptor Research 51:129-135.

Spaul, R. J. AnD J. A. HeATH. 2016. Nonmotorized recreation and motorized recreation in shrub-steppe habitats affects behavior and reproduction of Golden Eagles (Aquila chrysaetos). Ecology and Evolution 6:80378049.

Steenhof, K. and I. Newton. 2007. Assessing nesting success and productivity. Pages 181-192 in Raptor research and management techniques. Bird, D. M., K. L. Bildstein, D. R. Barber, and A. Zimmerman (Editors). Hancock House Publishers, Blaine, Washington, USA.

Steenhof, K., J. L. Brown, and M. N. Kochert. 2014. Temporal and spatial changes in Golden Eagle reproduction in relation to increased off highway vehicle activity. Wildlife Society Bulletin 38:682-688.

Steidl, R. J. and R. G. Anthony. 1996. Responses of Bald Eagles to human activity during the summer in interior Alaska. Ecological Applications 6:482-491.

Steidl, R. J. And R. G. Anthony. 2000. Experimental effects of human activity on breeding Bald Eagles. Ecological Applications 10:258-268.

Steidl, R. J., K. D. Kozie, G. J. Dodge, T. Pehovski, And E. R. Hogan. 1993. Effects of human activity on breeding behavior of Golden Eagles in Wrangell-St. Elias National Park and Preserve; a preliminary assessment. USDI, National Park Service, WRST Research and Resource Report 93-3. Wrangell-St. Elias National Park and Preserve, Copper Center, Alaska, USA.

Stien, J. And R. A. Ims. 2016. Absence from the nest due to human disturbance induces higher nest predation risk than natural recesses in Common Eiders Somateria mollissima. Ibis 158:249-260.

Strasser, E. H. And J. A. Heath. 2013. Reproductive failure of a human-tolerant species, the American Kestrel, is associated with stress and human disturbance. Journal of Applied Ecology 50:912-919.

Tarjuelo, R., I. Barja, M. B. Morales, J. Traba, A. Benítez-López, F. Casas, B. Arroyo, M. P. Delgado, AND F. Mougeot. 2015. Effects of human activity on physiological and behavioral responses of an endangered steppe bird. Behavioral Ecology 26:828-838.

Watson, J. 2010. The Golden Eagle. Second Edition. T. and A. D. Poyser, London, United Kingdom.

Watson, H., M. Bolton, and P. Monaghan. 2014. Out of sight but not out of harm's way: human disturbance reduces reproductive success of a cavity-nesting seabird. Biological Conservation 174:127-133.

Webber, A. F., J. A. Heath, and R. A. Fischer. 2013. Human disturbance and stage-specific habitat requirements influence Snowy Plover site occupancy during the breeding season. Ecology and Evolution 3:853863.

Weston, M. A., E. M. McLeod, D. T. Blumstein, And P.-J. GUAY. 2012. A review of flight-initiation distances and their application to managing disturbance to Australian birds. Emu 112:269-286.

Wiedmann, B. P. And V. C. Bleich. 2014. Demographic responses of bighorn sheep to recreational activities: a trial of a trail. Wildlife Society Bulletin 38:773-782. 